\title{
A experiência da pesquisa em comunicação ambiental e suas aplicações no estudo e na preservação do Pantanal sul-matogrossense ${ }^{1}$
}

\author{
Greicy Mara França* \\ Lairtes Chaves Rodrigues Filho**
}

Resumo: Este trabalho busca estabelecer bases teóricas e reflexões acerca da comunicação ambiental a partir da prática da pesquisa realizada em Mato Grosso do Sul, na preservação do bioma pantaneiro. A produção de notícias relacionadas ao Pantanal no território sulmatogrossense, além de se apresentarem minimamente nos jornais, recebe enfoques outros às questões ambientais, evidenciando que a área de preservação é entendida como área de exploração. Conclui-se, pela análise, que a angulação, presença e discurso das notícias relacionadas ao Pantanal surgem como instrumento de firma das questões econômicas, desvalorizando o bioma e as questões ambientais pertinentes.

Palavras-chave: Comunicação ambiental; jornalismo ambiental; sustentabilidade.

\section{The experience of research in environmental communication and its applications in the study and preservation of the Pantanal area in Mato Grosso do Sul}

\begin{abstract}
This paper wants to establish theoretical foundations and ideas about the environmental communication from the practice of research in Mato Grosso do Sul, in preserving the Pantanal biome. The production of news related to the Pantanal area in Mato Grosso do Sul, also is minimally present in the newspapers, as receive other approaches to environmental issues, showing that the preservation area is understood as the exploration area. It follows, by analysis, that the angle, presence and speech of news related to the Pantanal come as an instrument for firm economic issues, devaluing the biome and the relevant environmental considerations.
\end{abstract}

Keywords: Environmental communication; environmental journalism; sustainability.
Artigo recebido em: 10 de setembro de 2010 Aprovado em:

28 de setembro de 2010

\section{* Doutora em} Comunicação Social pela Universidade Metodista de São Paulo (UMESP). Coordenadora do Núcleo de Jornalismo Científico. Professora do Departamento de Jornalismo da UFMS. Líder do Grupo de Pesquisa do CNPq Mídias Ambientais.

greicymara@hotmail.com

** Bolsista de Extensão. Acadêmico do curso de Comunicação Social - Jornalismo da UFMS. Membro do Grupo de Pesquisa do CNPq Mídias Ambientais. Repórter do site CiênciaeNotícia, ligado ao Núcleo de Jornalismo Científico.

lairtes.filho.seeker@gmail.com

\footnotetext{
Uma primeira versão deste artigo foi apresentada no XXXIII Congresso Brasileiro de Ciências da Comunicação, 2010, sob o título "Inserção do Pantanal como área de preservação e conservação nas principais mídias impressas de Mato Grosso do Sul".
}

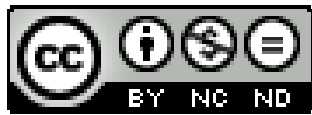




\section{Introdução}

egundo Belmonte, citado por Vilas Boas, (2004), a imprensa cumpre sem problema seu papel de informar, embora costume assustar a população. Mas, diante da crise ecológica, a imprensa também precisa assumir a responsabilidade de educar e transformar. Para o autor, o jornalismo ambiental não pode ser apenas informativo, tem de estar engajado em um modelo de vida sustentável do ponto de vista ecológico e social.

Informação e comunicação são noções que remetem a fenômenos sociais; as mídias são um suporte organizacional que se apossa dessas noções para integrá-las em suas diversas lógicas - econômica (fazer viver uma empresa), tecnológica (estender a qualidade e a quantidade de sua difusão) e semiótica (servir à democracia cidadã) (CHARAUDEAU, 2009).

Entendemos que a mídia tem em si a função social de educar a sociedade ao nível de valor, norma, informação e consciência. Entendemos ainda que a mídia de Mato Grosso do Sul, por estar intrinsecamente ligada à questão ambiental, tem a função de promover a valorização e a educação ambiental em suas pautas.

Conforme Left:

O ambiente emerge como um saber reintegrador da diversidade, de novos valores éticos e estéticos e dos potenciais sinergéticos gerados pela articulação de processos ecológicos, tecnológicos e culturais. O saber ambiental ocupa seu lugar no vazio deixado pelo progresso da racionalidade científica, como sintoma de sua falta de conhecimento e como sinal de um processo interminável de produção teórica e de ações práticas orientadas por uma utopia: a construção de um modelo sustentável, democrático, igualitário e diverso (LEFT, 1986 apud LEFT, 2001, s/p).

Segundo Rodrigues Filho e França (2010), ao promover a educação ambiental pela informação ampla, com linguagem e códigos adequados, os jornais evidenciam sua importância e função na valorização e formação políticoidentitária do Estado, possibilitando a identificação do leitor local ao bioma Pantanal, e suas implicações no desenvolvimento regional.

Analisar a prática (ou não) do jornalismo ambiental numa pauta que em si é ambiental e vincula várias outras áreas, torna-se essencial para entender os processos de construção do entendimento da realidade de desenvolvimento ou decréscimo da sustentabilidade, para a população do estado (RODRIGUES FILHO; FRANÇA, 2010. p. 3). 


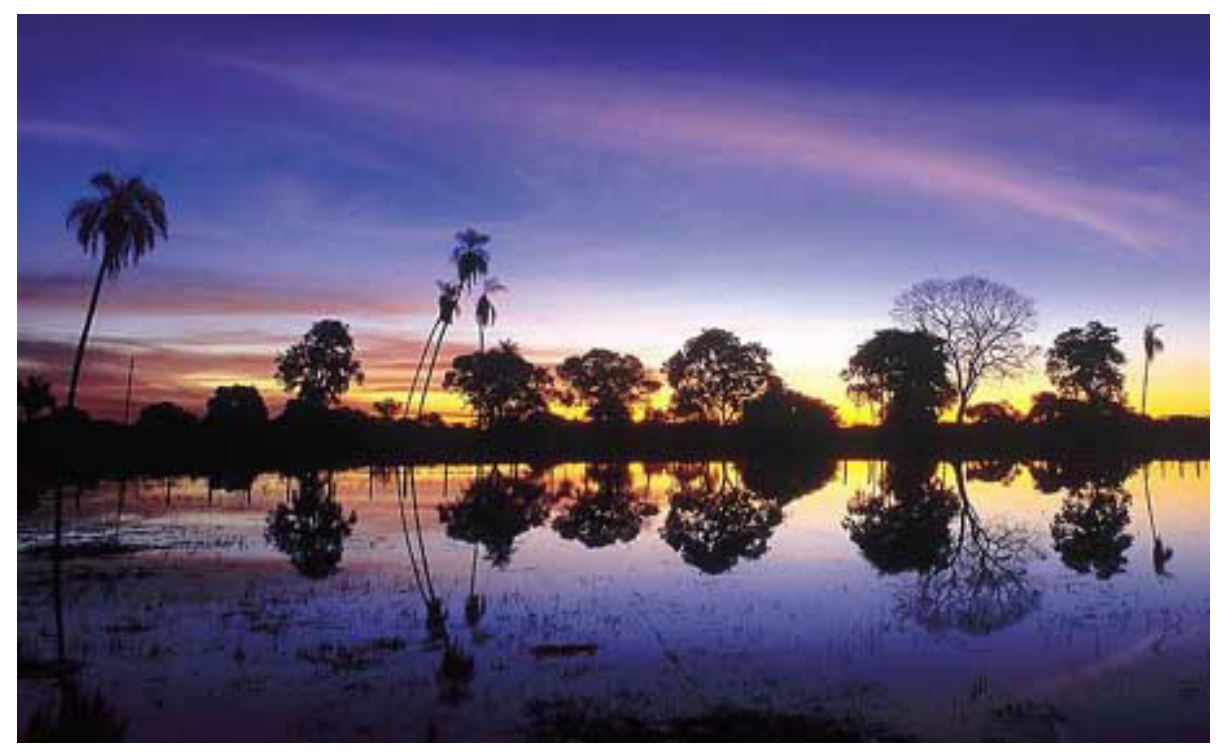

Foto 1 - Paisagem do Pantanal sul-matogrossense.

Fonte: http://opiniaoweb.com/viagens/wp-content/uploads/2009/06/pantanals1.jpg

\section{A Experiência com o Pantanal}

Os autores realizaram uma pesquisa a fim de estabelecer cientificamente e em que proporção as mídias impressas de Mato Grosso do Sul inseriam matérias ambientais, e quantas relacionavam o Pantanal como área de preservação e conservação, pesquisa essa divulgada no XXXIII Congresso Brasileiro de Ciências da Comunicação, em Caxias do Sul, sob o título de "Inserção do Pantanal como área de preservação e conservação nas principais mídias impressas de Mato Grosso do Sul”.

É fato conhecido de que o bioma pantaneiro não apenas molda a paisagem e a geografia do estado, mas também definiu e colaborou para a sua formação econômico-social-cultural. (...) Os meios de comunicação de massa, observam e fortalecem esse vínculo, que se inicia na dimensão ambiental e decorre em aspectos antropológicos (RODRIGUES FILHO; FRANÇA, 2010, p. 1-2).

Foram coletadas e monitoradas no período de 22 de março de 2010 a 6 de abril de 2010, notícias geradas ou produzidas na pauta do bioma pantaneiro e de jornalismo ambiental nos jornais diários "Correio do Estado" e "O Estado", veículos impressos de maior circulação no estado de Mato Grosso do Sul, quantificando e analisando as que, de fato, narram a pauta com foco ou suporte no Pantanal enquanto área de preservação e conservação.

A mídia em seu papel educacional, de vigilância e denúncia, deve possibilitar à população o acesso a informações científicas e ambientais, não apenas relacionando o jornalismo enquanto ato político de formação de consciência e qualificação da atuação do cidadão, como também configurando o mesmo, como garantia do direito humano à informação e a comunicação (RODRIGUES FILHO; FRANÇA, 2010, p. 9). 


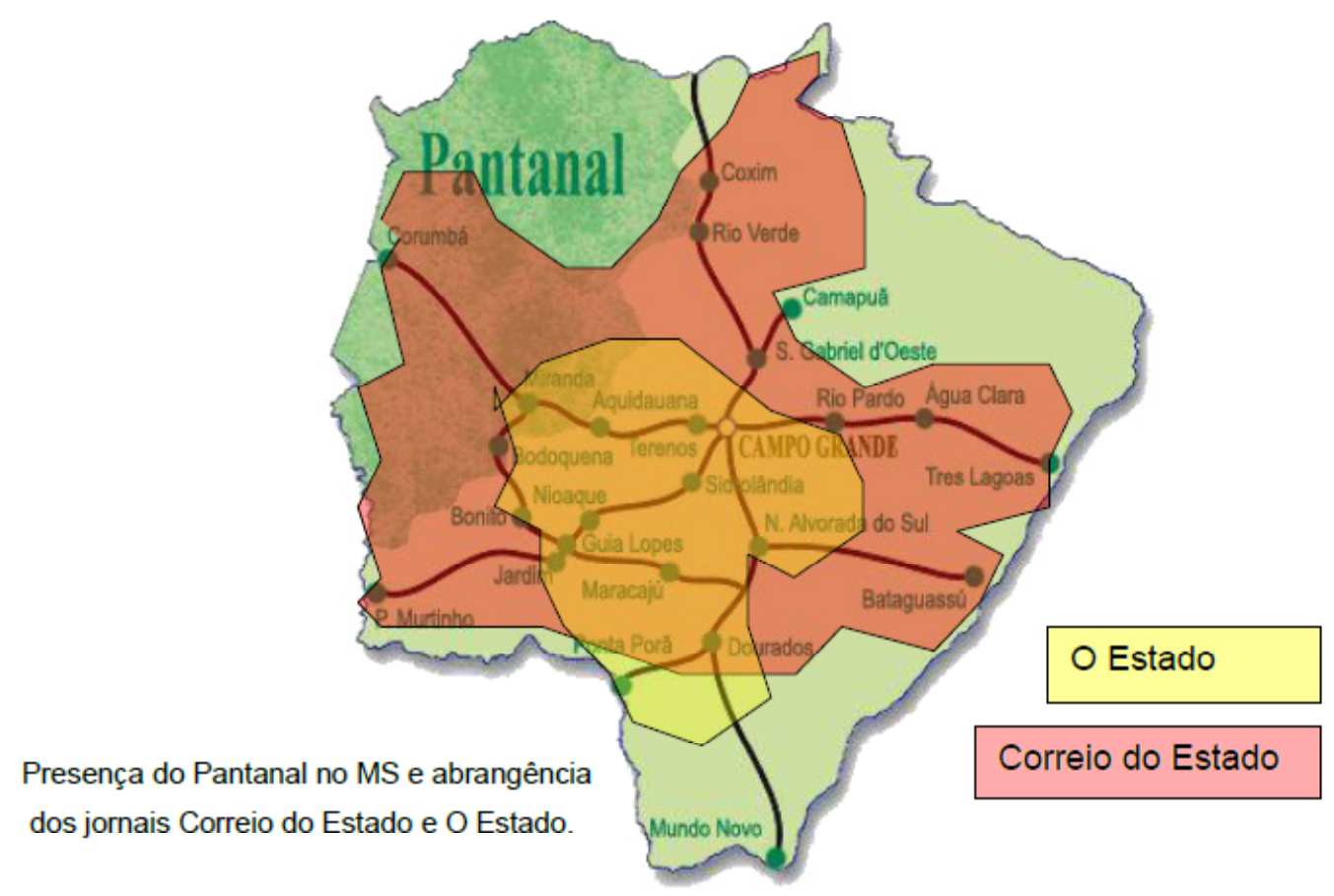

Gráfico 1. Presença do Pantanal no MS e abrangência dos jornais Correio de Estado e O Estado (RODRIGUES FILHO; FRANÇA, 2010, p. 4)

Num primeiro momento, essa pesquisa preocupou-se em quantificar estatisticamente o número de notícias de cada jornal e comparar o espaço que o jornalismo ambiental ocupava em cada um. Em seguida, realizou-se uma segunda análise, centrada na Análise do Discurso dos textos noticiosos, buscando estabelecer as relações de relevância e significação das pautas, comparando os dois veículos, num último momento, na quantidade, distribuição e conteúdo das noticias ambientais e, especificamente, as relacionadas ao Pantanal como área de preservação e conservação.

O desenvolvimento de notícias que considerem notícias na pauta pantaneira, com foco na questão ambiental, não apenas fomenta o desenvolvimento local, com a preocupação da sustentabilidade em todas as outras especificidades e editorias jornalísticas, como também, possibilita a integração do cidadão com seu próprio ambiente simbolicamente, pelos processos de ação midiática e codificação/decodificação (HALL, 2003 apud RODRIGUES FILHO; FRANÇA. 2010, p. 3).

Outra preocupação deu-se em analisar a inserção das notícias dentro do espaço gráfico dos jornais, seu tamanho, acompanhamentos de recursos visuais ou gráficos, se acompanham fotografias, legendas, boxes, recursos adicionais etc.; considerando a metade superior da página do jornal como posição de destaque e, a parte inferior como posição de complemento. Estas recebendo maior ou menor importância conforme seu posicionamento, se perto do centro da página ou em posição mais periférica. 


\section{Comparação da Quantidade de Notícias por Data}

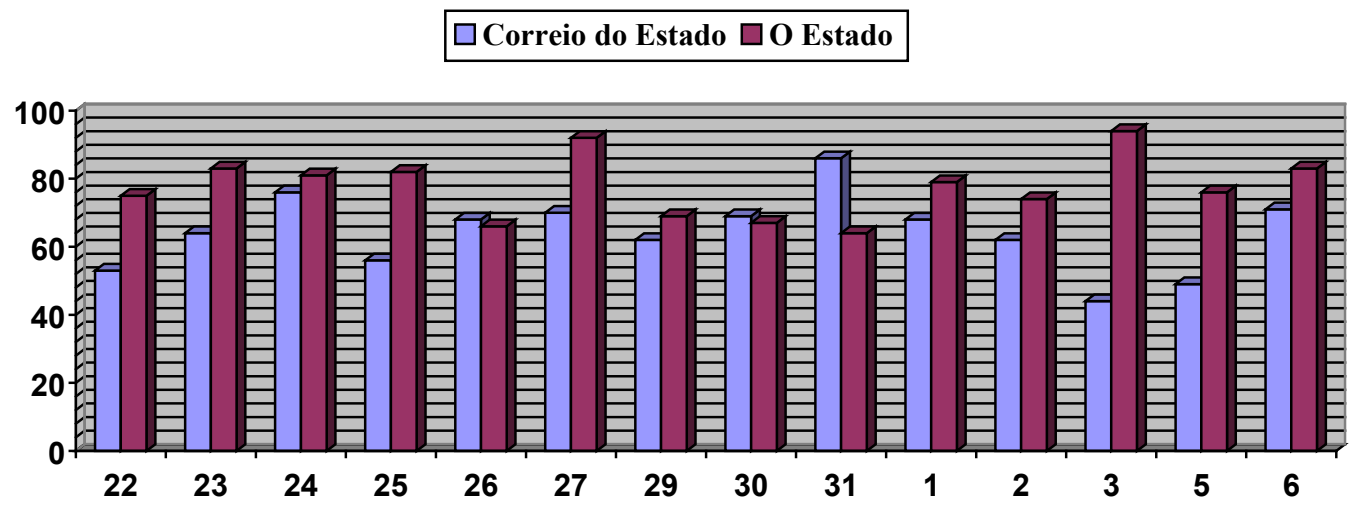

Gráfico 2. Comparação da quantidade de notícias por data. (RODRIGUES FILHO; FRANÇA, 2010, p. 5).

Os jornais, embora possuam linhas editoriais diferentes, tornaram-se muito semelhantes no que se refere à quantidade de notícias ambientais publicadas. De um modo geral, quando há a preocupação com a angulação e enfoque ambiental nas notícias relacionadas, estas sempre recebem presença secundária. Em posição inferior nas páginas dos impressos, nunca, ou quase nunca, são acompanhadas de fotografias, recursos visuais, boxes, ou qualquer recurso gráfico ou editorial para chamar e/ou prender a atenção do leitor. Nenhuma notícia ambiental recebeu mais que XXX toques, ou mais que um terço de coluna.

No jornal "Correio do Estado", de um total de 898 notícias, somadas ao longo de 15 dias consecutivos, com a presença de uma editoria e caderno sazonal específico de ecologia, apenas 4 (0,26\%) abordam o Pantanal enquanto área de preservação, entretanto sempre acoplada a um conjunto de interesses econômicos e políticos.

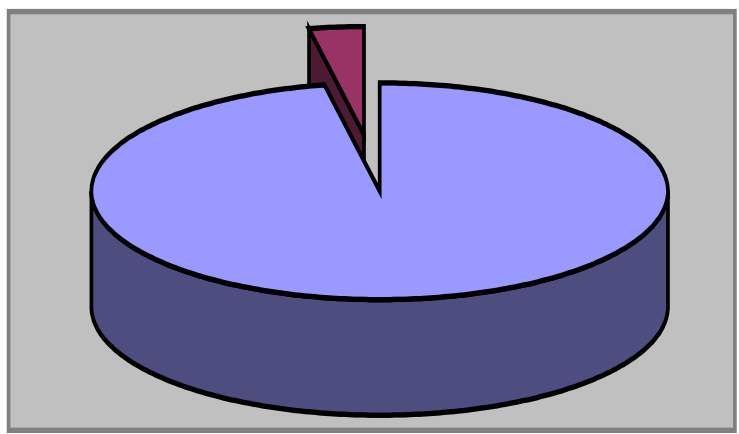

\section{口Total de notícias \\ पNotícias Ambientais}

Gráfico 3. Presença das notícias ambientais em comparação ao total de notícias no jornal "Correio do Estado". (RODRIGUES FILHO; FRANÇA, 2010, p. 5-6).

O impresso, embora mantenha um caderno sazonal específico de ecologia, pouco investe nas reportagens ou tratamento das informações ambientais e do Pantanal como notícia e pauta que mereça destaque nas páginas, tanto no posicionamento gráfico quanto na quantidade de notícias presentes. Evi- 
denciou-se a predominância dentro das notícias ambientais (3\%) de assuntos relacionados a catástrofes e problemas ambientais no exterior, pouco oportunizando a discussão de notícias locais, quando muito, ações da Polícia Militar Ambiental na fiscalização de rios e limpeza do lixo urbano.

No jornal "O Estado", de um total de 1085 notícias, também somadas ao longo de 15 dias consecutivas, sem editoria específica de meio ambiente, apenas $3(0,27 \%)$ se relacionavam ao Pantanal como área de preservação.

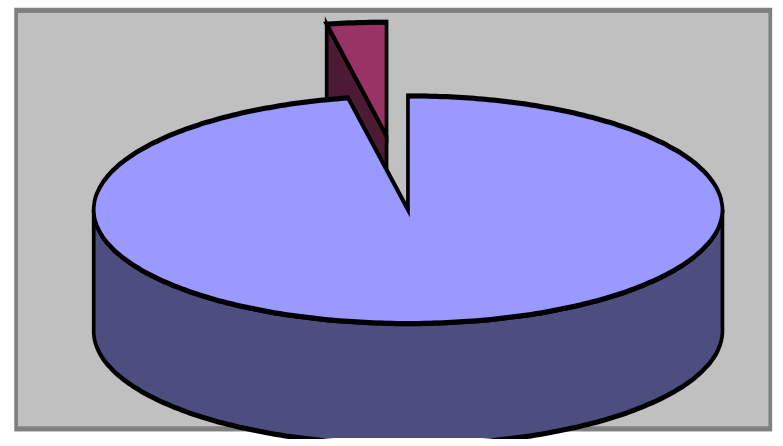

पTotal de notícias

口Notícias Ambientais

Gráfico 4. Presença das notícias ambientais em comparação ao total de notícias no jornal "O Estado". (RODRIGUES FILHO; FRANÇA, 2010, p. 7).

Não possui caderno ou editoria específica de meio ambiente, e pouco acrescenta em seus diários notícias ambientais, apesar do grande volume de notícias somados durante a pesquisa. Evidenciou-se a predominância de notícias ambientais gerais como aquecimento global, mudanças climáticas ou o problema das chuvas em todo o país e no Estado. A posição gráfica das notícias não favorece as notícias de meio ambiente, ou ainda sobre o Pantanal, essas últimas aparecendo nas partes superiores das páginas apenas quando relacionado a assuntos econômicos rurais.

A ausência das notícias relacionadas ao Pantanal como área de preservação e conservação, não apenas sugere a desvalorização do bioma, mas também sugere o antagonismo das questões ambientais na mídia, visto que esta apenas dá espaço a esses assuntos quando relacionados a escândalos, crimes, e ao espetáculo como um todo (RODRIGUES FILHO; FRANÇA, 2010, p. 9).

\section{Considerações finais}

A pesquisa em comunicação ambiental fomenta diretamente a contextualização das questões ambientais e suas implicações em todos os níveis de processos de formação do conhecimento. Entender como as mídias lêem as questões ambientais remete a preocupação de como as audiências lêem as mesmas e, logo, quais as implicações das leituras diversas na sociedade e no ambiente.

Da experiência de pesquisa com o bioma pantaneiro, apreende-se a experiência de exclusão por parte das mídias no que refere-se a preocupação com a formação coletiva de uma consciência ambiental que valorize não apenas as 
questões relacionadas à preservação e conservação, mas também aos aspectos culturais e econômicos que inferem diretamente sob o ambiente em questão.

O saber ambiental deve ser abordado e tornado significativo pelas mídias e pelos pesquisadores a fim de atuar na educação ambiental pela mídia, levando em consideração as relações e processos de interação simbólica entre ambiente e sociedade, mediados pelos sistemas de comunicação.

\section{Referências bibliográficas}

CHARAUDEAU, Patrick. Discurso das Mídias. $1^{a}$ ed. - São Paulo: Contexto, 2009.

HALL, Stuart. A identidade cultural na pós-modernidade. Rio de Janeiro: DP \&A. 2003. $7^{\text {a }} \mathrm{Ed}$.

LEFF, E. Saber Ambiental: sustentabilidade, racionalidade, complexidade, poder; tradução de Lúcia Mathilde Endlich Orth - Petrópolis, RJ: Vozes, 2001.

RODRIGUES FILHO, L.C.; FRANÇA, G.M. Inserção do Pantanal como área de Preservação e Conservação nas principais mídias impressas de Mato Grosso do Sul. In: XXXIII Congresso Brasileiro de Ciências da Comunicação, 2010, Caxias do Sul - RS. Anais do XXXIII Congresso Brasileiro de Ciências da Comunicação. São Paulo: INTERCOM, 2010. CD-ROM. VILAS BOAS, Sergio. Formação \& Informação Ambiental: Jornalismo para iniciados e leigos. São Paulo: Summus, 2004.

WOLF, Mauro. Teorias da comunicação. Lisboa: Presença, 1987. 